\title{
Type IV delayed-type hypersensitivity of the respiratory tract due to budesonide use: report of two cases and a literature review
}

\author{
*Constantinos Pitsios ${ }^{\mathrm{a}}$, Efthalia C Stefanaki ${ }^{\mathrm{a}}$, Arthur Helbling ${ }^{\mathrm{b}}$ \\ a Allergy Outpatient Department, Social Insurance Institute, Athens, Greece \\ b Division of Allergology, Department of Rheumatology, Clinical Immunology and Allergology, University Hospital, Bern, Switzerland
}

Received 16th April 2009; revised version received 18th May 2009; accepted 18th July 2009; online 13 th October 2009

\begin{abstract}
Respiratory type-IV hypersensitivity reactions due to corticosteroids is a rare phenomenon. We describe two such cases. The first is a $37-$ year-old atopic woman who developed labial angioedema and nasal itching after the use of budesonide nasal spray. A month later, after the first puffs of a formoterol/budesonide spray prescribed for asthma, she noticed symptoms of tongue and oropharyngeal itching and redness with subsequent dysphagia, labial and tongue angioedema, and facial oedema. The second is a 15-year-old non-atopic woman who reported pruritic eruptions around the nostrils after using a budesonide nasal spray. A year later she presented with nasal pruritus with intense congestion and labial and facial oedema after using the same spray. Both patients were evaluated with patch-tests using the commercial T.R.U.E. test ${ }^{\oplus}$, a budesonide solution, and corticosteroid creams. Test evaluation was performed at 48 and 96 hours. In both patients, patch tests were positive to budesonide $(++)$ on the second day. The first patient also had a positive $(+)$ reaction to tixocortol-21-pivalate. All the other patch tests were negative. Clinicians should be aware that hypersensitivity reactions may occur during the use of nasal or inhaled corticosteroids.

(C) 2010 Primary Care Respiratory Society UK. All rights reserved.

C Pitsios et al. Prim Care Resp J 2010; 19(2): 185-188

doi:10.4104/pcrj.2009.00061
\end{abstract}

Keyw ords corticosteroids, topical, inhaled, type-IV hypersensitivity reaction, budesonide, patch tests

\section{Introduction}

The extensive use of topical corticosteroids in medical practice has caused an increased frequency of contact dermatitis with a prevalence ranging from 0.5 up to $5 \%$. $^{1}$ Patch tests are the classical method for demonstrating a $\mathrm{T}$ cell-mediated allergic mechanism; sensitisation to corticosteroids can be reliably tested using a commercial epicutaneous test system such as the T.R.U.E. test ${ }^{\circledast}$ panel No III (ALK-Abellò A/S, Hørsholm, Denmark).

Allergic reactions caused by budesonide intranasal or inhaled sprays have been reported occasionally. ${ }^{2,3}$ They manifest as nasal congestion, local pruritus or nasal burning after using an intranasal spray, or as dry cough, dyspnoea and glossopharyngeal oedema following lung inhalation. Postulated unresponsiveness or symptom deterioration in response to the corticosteroid treatment may also be symptoms of corticosteroid allergy. ${ }^{4,5}$

Concentrations and vehicles for corticosteroid patchtesting have not been standardised yet, and the existing commercial T.R.U.E. test includes three corticosteroids, namely budesonide, tixocortol-21-pivalate and hydrocortisone-17-butyrate. In this paper, we present two case reports of a delayed-type form of contact hypersensitivity reaction due to budesonide in both nasal spray and inhaler formulation, as well as the diagnostic procedures employed.

\section{Case reports Patient 1}

A 37-year-old house-dust mite allergic woman, with rhinoconjunctivitis and asthma, reported labial angioedema and nasal itching three days after treatment with a budesonide aqua nasal spray. Symptoms ceased when she

\footnotetext{
* Corresponding author: Dr Constantinos Pitsios, Ipsilantou 32, 11521 Athens, Greece

Fax: +30 2107211831 E-mail: pitsios@yahoo.com
} 
stopped treatment. She had also used a budesonide nasal spray in the past (she couldn't define how many years ago) with no side-effects. A month after this first episode she was commenced on treatment with formoterol/budesonide dry powder inhaler for treatment of an asthma exacerbation. Four hours after inhaling two puffs she noticed an unusual itch on her tongue. Six hours after the next inhalation she experienced oropharyngeal itching and redness of the face. Although she stopped the inhalation treatment, symptoms remained, and 18 hours later she visited the Emergency Department presenting with dysphagia, tongue angioedema and facial oedema. Symptoms remitted two hours after treatment with oxygen, intravenous methyl-prednisolone and inhaled salbutamol.

\section{Patient 2}

A 15-year-old female, with no former history of atopy or other allergy, was referred because of massive nasal congestion, pruritic papular erythema on her nose and cheeks, and labial and facial oedema, which presented 24 hours and 13 hours, respectively, after use of a budesonide nasal spray (two puffs per nostril each time) on two recent occasions. She also reported worsening rhinitis with pruritic eruptions around the nostrils after using the same spray for the first time about a year previously; she had not used the spray in the intervening period.

\section{Diagnostic procedures}

Both patients were suspected of having corticosteroid hypersensitivity. Patch tests were performed according to the European standard series using the commercial T.R.U.E. test ${ }^{\oplus}$. In addition budesonide $(0.25 \mathrm{mg} / \mathrm{ml}$ solution) was dispensed in petrolatum, and corticosteroid creams or ointments (see Table 1) were applied in Finn Champers, on clinicallyuninvolved skin on the back. All four groups of cross-reacting corticosteroid molecules were tested; two hydrocortisone-

\section{Table 1. Patch tests performed.}

\begin{tabular}{llllll}
\multicolumn{2}{l}{ Corticosteroids } & Patient 1 & \multicolumn{2}{l}{ Patient 2} \\
\hline Groups & Substances & D2 & D4 & D2 & D4 \\
\hline A & Cr. Hydrocortisone acetate 1\% & - & - & - & - \\
A & $\left(T^{*}\right)$ Tixocortol-21-pivalate & + & + & - & - \\
B & Cr. Fluocinolone acetonide 0.01\% & - & - & - & - \\
B & Sol. Budesonide 0.25mg/ml (Petr)** & ++ & ++ & ++ & ++ \\
B & (TT) Budesonide & ++ & ++ & ++ & ++ \\
C & Oint. Dexametasone phosphate 0.2\% & - & - & - & - \\
D1 & Cr. Mometasone furoate 0.1\% & - & - & - & - \\
D1 & Oint. Betametasone valerate 0.1\% & - & - & - & - \\
D2 & (TT) Hydrocortisone-12-butyrate & - & - & - & - \\
\hline
\end{tabular}

*TT: T.R.U.E. test, **Petr: Petrolatum type corticosteroids (group A), acetonides of group B, a betametasone-type non-esterified corticosteroid from group $C$, and esters/butyrate-type hydrocortisone from group D. ${ }^{6}$ Budesonide belongs to the acetonide group $B$, and was also included. Petrolatum was used as a negative control test. No medications (short- or long-acting anti-histamines, oral or systemic corticosteroids, or topical corticosteroids at the test application sites) or UV-therapy had been used by the patients in the previous four weeks.

The patch tests were removed 48 hours later and skin reactions were read on Day 2 and 4 (96 hours later). A skinprick test using the budesonide nebuliser-solution $(0.25$ $\mathrm{mg} / \mathrm{ml}$ ) was also performed on the forearm of the patients to exclude type I hypersensitivity reactions.

\section{Results}

Reactions were scored according to the International Contact Dermatitis Research Group (ICDRG) criteria.' On day 2 both patients presented a positive reaction with infiltration, papules and vesicles $(++)$ to budesonide with the TRUE test and the nebuliser solution (see Table 1). Patient 1 also had a positive reaction with erythema, papules and infiltration (+) to tixocortol-21-pivalate. All positive skin test reactions remained of a similar grade on day 4. All other patch tests were negative. As expected, skin-prick test to the budesonide solution was negative in both patients. A catalogue of proposed corticosteroid medications was provided to these patients. During the following months Patient 1 reported the safe and efficacious use of mometasone cream.

\section{Discussion}

Oropharyngeal involvement (soreness, candidiasis), cough, dyspnoea and hoarseness are some commonly known sideeffects attributed to the use of inhaled costicosteroids. Although in most cases no such immunological mechanism is involved, clinicians should be aware that delayed type-IV hypersensitivity reactions (according to the Gell-Coombs classification) to corticosteroids can occur.

The occurrence of corticosteroid allergy has been investigated in a group of adult asthmatics presenting local oropharyngeal irritation, hoarseness, skin symptoms, cough and dyspnoea after the use of inhaled corticosteroids; patch tests proved positive in only two out of a total of 51 patients who had been patch-tested. ${ }^{8}$ Negative patch tests confirmed the absence of contact dermatitis in the rest of the patients, suggesting that hypersensitivity reactions represent about $5 \%$ of the side-effects of inhaled corticosteroids.

Only in two cases of late onset allergy to budesonide has an IgE-mediated mechanism been postulated, but this has not been confirmed. ${ }^{9,10}$ In the case of a 24-year-old man, a budesonide solution was rubbed on the anterior side of his 
forearm resulting in a negative reaction 20 minutes later and a positive reaction five hours later, while no immediate reaction was observed with the "Scratchtest". 9 In the case of a 59-year-old woman the Immunospot-modified dot blot analysis proved positive to budesonide aqueous solution but negative to human serum albumin conjugate of budesonide and the budesonide dry powder sample. ${ }^{10}$ Prick and scratch tests were also negative.

All published papers on budesonide allergy describe a late onset reaction after administration of inhaled or nasal budesonide, leading to the diagnosis of a $\mathrm{T}$ cell-mediated mechanism. ${ }^{2,3,8,11}$ The use of patch tests has confirmed the fact that they were all type-IV hypersensitivity reactions, even in the aforementioned two cases which were reported as being IgE-mediated..$^{9,10}$

Contact sensitisation to a substance begins with the local application to the skin or mucosa of a chemically reactive substance which penetrates and forms covalent bonds with proteins. The hapten-protein complex is ingested by dendritic cells that present it to Th1 cells, which get sensitised and start to proliferate. Thus, $\mathrm{T}$ cells are undergoing an anamnestic response, and after re-exposure to that specific substance contact dermatitis - or mucosal involvement of other organs - is noticed.

The use of nasal or inhaled corticosteroids in a patient with type-IV allergy may not only cause respiratory symptoms but also skin reactions. Dermatitis may flare up on the skin where local corticosteroids have been used in the past. An interesting paper assessed whether inhalation of budesonide may reactivate former patch test reactions caused by budesonide; ${ }^{5}$ the authors noticed that in patients with positive patch tests to budesonide (performed six weeks earlier) flare-up reactions reappeared within 24 hours after the inhalation of budesonide. The severity of the reactions correlated with the intensity of the previous patch test. The authors also reported that asthmatic patients were more likely to present budesonide hypersensitivity $(1.8 \%)$ than patients with dermatitis $(1 \%) .^{5}$

Corticosteroids are divided into four main molecular groups. Cross-reactions among corticosteroids may be observed due to similarities between the molecules. Corticosteroid cross-reactions included in the T.R.U.E. test panel are common even if the patient has not used a particular product or had any problems with it before. ${ }^{12}$ This explains the positive test to tixocortol in Patient 1, although no former use of this medicine was reported by the patient.

It appears that cross-reactivity does not always correlate with the corticosteroid molecular grouping. Case reports of cross-reactivity among corticosteroids of different groups for example, between budesonide and desoximetasone (group C) or mometasone furoate (group D1) - have been reported. ${ }^{13,14}$ Patch-testing is a safe method to exclude or to permit future use of a corticosteroid in the context of a history of type-IV hypersensitivity reactions to any corticosteroid.

A question remains regarding the use of patch-testing as a screening test in patients with rhinitis or asthma. Two studies have already been performed. ${ }^{5,15}$ In these studies only one out of 99 patients showed contact allergy to tixocortol and, on further investigation, to budesonide. ${ }^{5}$ These results led to the conclusion that patch-testing to corticosteroids as a screening test for patients who have formerly used corticosteroids for rhinitis or asthma, is not useful. On the other hand, in asthmatic patients who have a first appearance of skin lesions after the use of inhaled corticosteroids, a delayed hypersensitivity reaction is a possibility and should be considered. ${ }^{16}$ The use of budesonide as an inhalant should be avoided in a patient already hypersensitive to it. ${ }^{16}$

In summary, physicians should be aware that allergy to corticosteroids used for the treatment of the respiratory tract may occur. In most reported cases the reactions are of lateonset. Diagnosis can be made using commercial patchtesting. In cases of type-IV corticosteroid hypersensitivity, a different corticosteroid indicated by a negative patch test result, should be used.

\section{Conflict of interest declaration}

All authors declare that they have no conflict of interest with regard to this study.

\section{References}

1. Matura M, Goosens A. Contact allergy to corticosteroids. Allergy 2000, 55:698. http://dx.doi.org/10.1034/j.1398-9995.2000.00121.x

2. Meding B, Dahlberg E. Contact allergy to budesonide in a nasal spray. Contact Dermatitis 1986;14:253-4. http://dx.doi.org/10.1111/j.1600-0536.1986. tb01241.x

3. Garcia-Abujeta JL, Fernandez L, Maquiera E, et al. Contact allergy to budesonide in an oral spray. Contact Dermatitis 1995;32:253. http://dx.doi.org/10.1111/j.1600-0536.1995.tb00689.x

4. Peris-Tortajada A, Giner A, Perez C, Hernandez D, Basomba A. Contact allergy to topical budesonide. J Allergy Clin Immunol 1991;87:597-8. http://dx.doi.org/10.1016/0091-6749(91)90021-F

5. Isaksson M, Bruze M, Hörnblad $Y$, Svenonius $E$, Wihl J $\AA$. Contact allergy to corticosteroids in asthma/rhinitis patients. Contact Dermatitis 1999;40:327. http://dx.doi.org/10.1111/j.1600-0536.1999.tb06086.x

6. Goossens A, Matura M, Degreef H. Reactions to corticosteroids: some new aspects regarding cross-sensitivity. Cutis 2000;65:43-5.

7. Wilkinson DS, Fregert $\mathrm{S}$, Magnusson B, et al. Terminology of contact dermatitis. Acta Dermato-Venereol 1970;50:287-92.

8. Kilpiö K, Hannuksela M. Corticosteroid allergy in asthma. Allergy 2003;58: 1131-5. http://dx.doi.org/10.1046/j.1398-9995.2003.00297.x

9. Fuchs $T$, Uter W, Sprotte U. Generalisierte urticaria durch budesonidverzögerte, lgE-vermittelte sofortreaktion? Allergologie 1991;14:234-8.

10. Lauerma Al, Kiistala R, Makinen-Kiljunen S, Haahtela T. Allergic skin reaction after inhalation of budesonide. Clin Exp Allergy 1993;23:232-3. http://dx.doi.org/10.1111/j.1365-2222.1993.tb00888.x

11. Isaksson M. Skin reactions to inhaled costocosteroids: incidence, avoidance and management. Drug Safety 2001;24:369-73. http://dx.doi.org/ 
C Pitsios et al.

10.2165/00002018-200124050-00003

12. Ferguson AD, Emerson RM, English JS. Cross-reactivity patterns to budesonide. Contact Derm 2002;47:337-40. http://dx.doi.org/10.1034/j.16000536.2002.470604.x

13. Räsänen $L$, Tuomi ML. Cross-sensitization to mometasone furoate in patients with corticosteroid contact allergy. Contact Dermatitis 1992;27:323-5. http://dx.doi.org/10.1111/j.1600-0536.1992.tb03290.x

14. Donovan JC, Dekoven JG. Cross-reactions to desoximetasone and mometasone furoate in a patient with multiple topical corticosteroid allergies. Dermatitis 2006;17:147-51. http://dx.doi.org/10.2310/6620.2006.05053

15. Wilkinson SM, Higgins B, Owen S, Mattey D, Woodcock A. An assessment of steroid hypersensitivity in asthma. Respir Med 1997;91:231-3. http://dx.doi.org/10.1016/S0954-6111(97)90043-3

16. Isaksson M, Bruze M, Hörnblad Y, Svenonius $E$, Wihl JA. Conact allergy to corticosteroids in asthma/rhinitis patients. Contact Dermatitis 1999;40:327. http://dx.doi.org/10.1111/j.1600-0536.1999.tb06086.x

Available online at http://w ww.thepcrj.org

A superb opportunity for all members of the primary care team to update their knowledge, discuss the optimal care of patients with respiratory diseases, and network with primary care respiratory clinicians and researchers

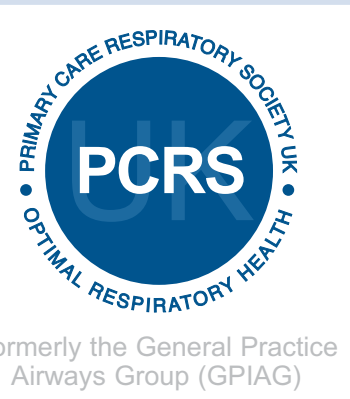

The Premier Respiratory Conference for Primary Care

\section{Optimal Respiratory Health:} Leading the way

10th-11th September 2010 Telford International Centre

Developed by leading primary care respiratory experts for primary care, the programme offers:

Essential clinical updates on asthma and COPD

Insights into the impact of lung disease and guidance on spotting those rarer respiratory conditions

$$
\bullet
$$

The more complex clinical and service delivery issues (in conjunction with IMPRESS)

The latest respiratory and original audit/research presentations (in conjunction with the PCRJ)

$$
\text { Practical "how to" workshops }
$$$$
\bullet
$$

The opportunity to learn how others are tackling the challenges of the new NHS environment in respiratory medicine

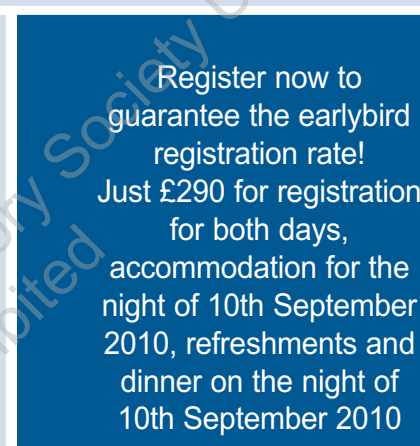

\section{PLUS}

Free membership to the PCRS-UK for the remainder of the calendar year for those healthcare professionals working in primary care in the UK.

For further information, please visit our website to download the

conference programme and register online:

www.pcrs-uk.org/

conferences/index.php;

Tel: 0121351 4455;

Email: info@pcrs-uk.org 